Research Article

\title{
Influence of a Two-Stage Sintering Process on Characteristics of Porous Ceramics Produced with Sewage Sludge and Coal Ash as Low-Cost Raw Materials
}

\author{
Esam Al-Qadhi $(\mathbb{D}$, Gaiye Li $(\mathbb{D}$, and Yaxing Ni \\ College of Mechanics and Materials, Hohai University, Nanjing 211100, China \\ Correspondence should be addressed to Gaiye Li; ligaiye@126.com
}

Received 26 May 2019; Revised 31 July 2019; Accepted 23 September 2019; Published 12 November 2019

Academic Editor: Antonio Riveiro

Copyright (C) 2019 Esam Al-Qadhi et al. This is an open access article distributed under the Creative Commons Attribution License, which permits unrestricted use, distribution, and reproduction in any medium, provided the original work is properly cited.

\begin{abstract}
In this paper, the two-stage sintering process as a promising strategy has been adopted to prepare high-performance porous ceramics with high porosity. Sewage sludge and waste coal ash were used as raw materials and added were starch and $\mathrm{CaCO}_{3}$ as a mixed foaming agent. The chemical composition of the raw materials and mixed foaming agents were analyzed by standard techniques. All mixtures were prepared from fixed solid materials mixed at a ratio of $48: 32: 10: 10$ (wt.\%) for coal ash, sludge, starch, and $\mathrm{CaCO}_{3}$, respectively, followed by granular molding, aging, sintering and property survey tests. The influence of heating rate, holding time, and heating temperature of the two stages on the characteristics of the as-obtained porous ceramics was deeply investigated. The properties investigated are apparent porosity, bulk density, compressive strength, and linear shrinkage. On the one hand, the results show that the major content of the raw materials is silica $\left(\mathrm{SiO}_{2}\right)$. On the other hand, the results show that the first-stage sintering process had minimal influence on the properties, whereas the second-stage sintering process had a significant influence on the properties of the porous ceramics. With the optimized sintering parameters (temperature, heating rate, and holding time) of the first stage and second stage, we obtained a high-performance porous ceramic product with an apparent porosity up to $51.3 \%$, bulk density up to $1.22 \mathrm{~g} / \mathrm{cm}^{3}$, linear shrinkage up to $14.3 \%$, and compressive strength up to $25.1 \mathrm{MPa}$. Also, the results of the phase composition and microstructure revolution showed sufficient glassy phases and feldspar $(\mathrm{Ca}, \mathrm{Na})(\mathrm{Si}, \mathrm{Al})$ $4 \mathrm{O}_{8}$, which are known to enhance bending strength of ceramics. A comparison of these properties and characteristics with those of standard porous ceramics revealed that the product developed in this study would compete favorably for real applications.
\end{abstract}

\section{Introduction}

The contradiction between industry development and environmental protection has become more and more intense in recent years [1]. As a representative example, aluminum siliceous waste and resultant slime from urban sewage treatment had dependably been a troublesome ecological issue $[2,3]$. Although many methods have been used to the dispose of wastes, such as landfill, agricultural compost, and incineration composting [4], secondary pollution to the earth and groundwater often happens due to the persistent organic pollutants and heavy metal infiltration [5]. Therefore, sintering wastes into porous ceramics has become one of the best ways to dispose of wastes in recent years [6], conforming to the concept of $3 \mathrm{R}$ system of reusing, reducing, and recycling.

Porous ceramics are used in many applications, such as bioceramics, gas membranes, thermal insulators, radiant gas burners, catalyst supports, particle filters, and many other fields [7-10] that demand high resistance to thermal stress, wear, and corrosion that are unobtainable from metals and polymers $[11,12]$. The use of recycled coal ash [13] and sewage sludge [14] to produce porous ceramics has enticed a lot of global interest due to the increased sewage sludge and coal ash production and the limitation of land available to produce ceramics $[15,16]$. Thus, it is considered as a practical solution for problems such as cost expenditure on waste management and its impact on the environment [17]. 
At the same time, porous ceramics with high strength and high porosity are much anticipated in real applications, but the two key factors are usually competing with each other $[18,19]$. Many alternatives have been investigated to improve characteristics of ceramics such as microstructure, compressive strength, and porosity of the ceramics by controlling the powder size, as well as changing their composition and treating methods [20, 21]. Among such efforts, the sintering parameters of ceramic materials by sintering curve control are much more preferred as a simple, effective, and relatively low-cost strategy [22].

Earlier studies have tried to fabricate porous ceramics from sludge waste together with clay or coal ash by combining the preheating and sintering treatments as one process [23]. This is quite limited for real applications presently due to the strategic resource constraints of clay and the competing porosity and strength restraints [24-28]. As a promising method to obtain microstructure-tailored ceramics to enhance the mechanical, electrical, magnetic as well as piezoelectric properties [29], the two-step sintering strategy has been successfully applied elsewhere to consolidate structural ceramics, bioceramics, ferrites, piezoelectric ceramics, and electrolyte ceramics [30, 31]. For the consolidation of sewage sludge-containing wastes, such a twostep strategy should be much more useful by preheating treatment at low sintering temperature to decompose the organic compounds and sintering at a higher temperature for making pores [32]. The kinds of foam agent and parameters are not the same. Especially for porous preparation ceramic with waste sewage sludge and coal ash, the secondhand waste cannot be obtained. The extensive literature review has little information about the effect of a two-stage heating process (preheating, sintering temperature, heating rate, and holding time) on the properties of porous ceramics produced with sewage sludge as raw materials.

Therefore, for this aim, we adopted a two-step strategy for the manufacture of high-performance porous ceramics using sewage sludge and coal ash as a low-cost raw material. Also, starch/ $\mathrm{CaCO}_{3}$ was added to act as a mixed foaming agent.

\section{Raw Materials and Methods}

2.1. Raw Materials. Sewage sludge used in this study was taken from the Sewage Treatment Plant of Jiangning Development Zone in Nanjing, and coal ash from the Power Plant in Maanshan of China. Table 1 shows the chemical components of coal ash and sewage sludge. As shown in Table 1, the chemical components of coal ash are mainly contained from $\mathrm{SiO}_{2}, \mathrm{Al}_{2} \mathrm{O}_{3}$ (accounting $83.7 \%$ of the total), and a small amount of $\mathrm{Fe}_{2} \mathrm{O}_{3}, \mathrm{CaO}$, and $\mathrm{K}_{2} \mathrm{O}$. The main chemical components of sewage sludge are $\mathrm{SiO}_{2}, \mathrm{Al}_{2} \mathrm{O}_{3}$, $\mathrm{CaO}$, and $\mathrm{Fe}_{2} \mathrm{O}_{3}$, in which $\mathrm{SiO}_{2}$ and organic matter accounted for the majority.

2.2. Preparation of the Porous Ceramic Samples. All mixtures were prepared from fixed solid materials mixed at a ratio of $48: 32: 10: 10$ (wt.\%) for coal ash, sludge, starch, and $\mathrm{CaCO}_{3}$, respectively. $\mathrm{NaOH}$ solution of $20 \mathrm{~g} / \mathrm{L}$ was also added and mixed well for better consolidation. Figure 1 shows the preparatory process of the porous ceramic samples described as follows:

(1) Raw material processing: the sludge taken from the sewage treatment plant was block-shaped, directly crushed, and sealed for use.

(2) Ingredients: the coal ash, sewage sludge, poreforming agent, and admixture were mixed according to the design formula, and stirred with a mixer.

(3) Granulation molding: freshly mixed material with adequate viscosity was transferred to a pelletizer disk for making the desired spherical pellet size. The uniformly mixed mixture was taken out, placed in a mortar, added with an appropriate amount of water, stirred again, pressed and formed by a custom mold, and pressed into a sample having a diameter of $20 \mathrm{~mm}$ and a height of $20 \mathrm{~mm}$. The molding pressure was set at $0.03 \mathrm{MPa}$, and the holding time 5 seconds.

(4) Aging: the sample was allowed to stand for 6 to 10 hours so that the starch can be fully gelatinized to improve the bonding degree of the whole pattern.

(5) Sintering: the pressed sample is placed in a box-type horse boiling furnace and sintered according to a self-designed sintering temperature mounting system. The sintering process is divided into two stages, according to the pore-forming mechanism. The implementation steps of the two-stage sintering method are designed to study the effects of sintering temperature, heating rate, and holding time on the properties of the products.

For the first-stage sintering process, the temperature was set at $300^{\circ} \mathrm{C}-700^{\circ} \mathrm{C}$, the heating rate was set at $1,3,5,7$, and $9^{\circ} \mathrm{C} / \mathrm{min}$, and the holding time was set at $0,5,10,15$, and $20 \mathrm{~min}$, respectively. The primary purpose of the first-stage sintering of the pellets was to eliminate the organic compounds in the sewage sludge and gradually study the effects of the sintering process.

For the second-stage process, the pellets were sintered at different temperatures ranging from $950^{\circ} \mathrm{C}$ to $1150^{\circ} \mathrm{C}$ with a heating rate set at $1,3,5,7$, and $9^{\circ} \mathrm{C} / \mathrm{min}$, and held at $0,5,10$, 15 , and $20 \mathrm{~min}$, respectively.

\subsection{Characterization of the Raw Materials and Products.} The phase composition of the raw materials and the assintered products were characterized by X-ray diffraction (X-ray diffraction, BrukerAXS-D8) at a rate of $10^{\circ} \mathrm{C} / \mathrm{min}$ from $5^{\circ}$ to $90^{\circ}$ at a voltage of $40 \mathrm{kV}$, a current of $40 \mathrm{~mA}$, and a test accuracy $\leq 0.02^{\circ}$. Then, phase composition, according to the XRD patterns, was analyzed with MDI-JADE software. The microstructural morphology was observed by scanning electron microscopy (SEM, Hitachi SU8020, Japan) equipped with energy dispersive spectroscopy (EDS). The weight and the heat change of mixed powders were recorded by a thermogravimetric-differential thermal scanning synchronous thermal analyzer (TG/DSC, US Discovery SDT 650 
TABLE 1: The chemical composition of coal ash and sewage sludge.

\begin{tabular}{lcccccccc}
\hline Chemical composition & $\mathrm{SiO}_{2}$ & $\mathrm{Al}_{2} \mathrm{O}_{3}$ & $\mathrm{CaO}$ & $\mathrm{Fe}_{2} \mathrm{O}_{3}$ & $\mathrm{MgO}$ & $\mathrm{K}_{2} \mathrm{O}$ & $\mathrm{P}_{2} \mathrm{O}_{5}$ & $\mathrm{Balance}$ \\
\hline Sewage sludge & 29.33 & 19.28 & 25.58 & 10.95 & 3.74 & 1.54 & 4.37 & 5.21 \\
Coal ash & 50.69 & 32.99 & 4.64 & 5.33 & 0.60 & 1.42 & 0.31 & 4.20 \\
\hline
\end{tabular}

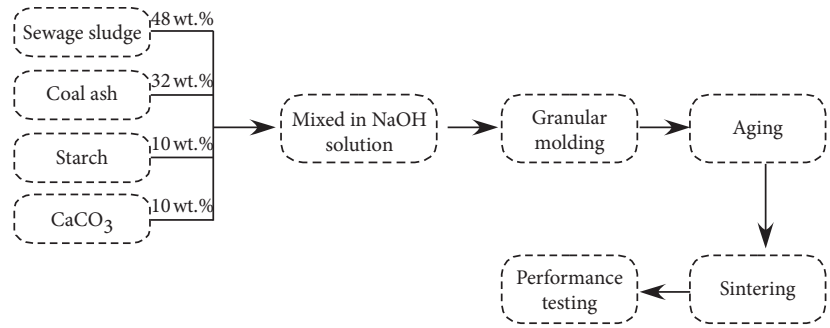

Figure 1: Preparatory flowchart for the porous ceramic samples.

type). The heating was conducted in the air from room temperature to $1200^{\circ} \mathrm{C}$ at $10^{\circ} \mathrm{C} /$ minute.

Porosity and bulk density of the porous ceramics were tested by the boiling drainage method GB/T 1966-1996 [33]. Shrinkage was determined by measuring the change in the diameter of the prepared sample before and after sintering.

The compressive strength is determined by using the universal material testing instrument REGER-3010 with the national standard of GB/T 1964-1996 [33]. The pattern was placed at the center of the universal testing machine, and the load was applied at a rate of $0.2 \mathrm{~mm} / \mathrm{min}$ until the pattern was broken. The pore size distribution was examined by mercury intrusion porosimetry (AutoPore IV 9500, Micromeritics Instrument Corporation).

\section{Results and Discussion}

3.1. Raw Materials Analysis. Figure 2 shows the results of $\mathrm{X}$-ray diffraction analysis of the mineral composition of coal ash and sludge. As indicated in Figure 2, according to the analysis of related material phase, the mineral coal ash is mainly composed of $\mathrm{SiO}_{2}$ and mullite $\left(\mathrm{Al}_{6} \mathrm{Si}_{2} \mathrm{O}_{13}\right)$ formed by the combination of silica $\left(\mathrm{SiO}_{2}\right)$ and alumina $\left(\mathrm{Al}_{2} \mathrm{O}_{3}\right)$. The presence of $\mathrm{Ca}$ element from sludge, $\mathrm{Al}$ from coal ash, and $\mathrm{Si}$ from both was also proved. Also, in Figure 2, it can be noticed that a large number of silicate glass phases exist in coal ash. The existence of $\mathrm{CaCO}_{3}$ in the sludge was due to the artificial addition of lime to improve the dewatering rate and deodorization of the sludge, whereas the sludge mainly contains $\mathrm{SiO}_{2}$, feldspar, and $\mathrm{CaCO}_{3}$.

Figure 3 shows the SEM morphology of sewage sludge and coal ash. As shown in SEM images of Figures 3(a) and 3(b), the morphology of the coal ash looks like a standard spherical structure. On the other hand, as shown in Figures 3(c) and 3(d), the morphology of the sewage sludge looks lose with irregularity in shapes and sizes. Also, the particle volume of the sewage sludge is much larger than that of coal ash. These morphologies are consistent with those found elsewhere [34].

Figure 4 shows the thermogravimetric analysis of the mixture of sludge and coal ash. As shown in Figure 4, first, due to an increase in the temperature to $200^{\circ} \mathrm{C}$, the weight loss was

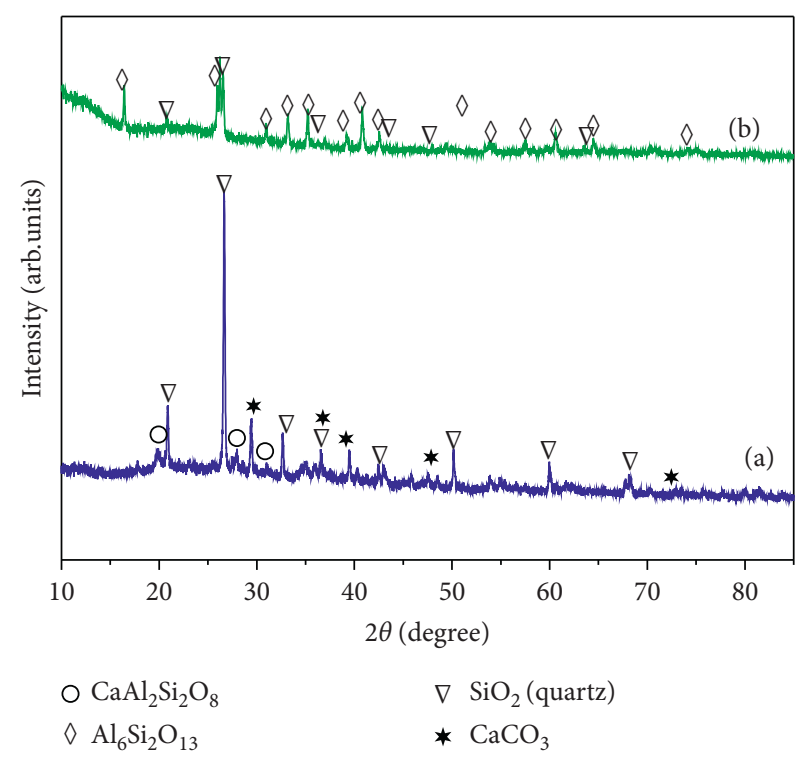

FIGURE 2: X-ray diffraction patterns of (a) sewage sludge and (b) fly ash.

$-7.9 \%$, mainly due to the evaporation of free water. Second, due to an increase in the temperature from $200^{\circ} \mathrm{C}$ to $600^{\circ} \mathrm{C}$, the weight loss was $-12.69 \%$, mainly due to the combustion of organic matters. Simultaneously, during the sintering process in this temperature range, the mixture releases most of its energy. Therefore, it is necessary to reduce the heating rate during this temperature range. Primarily, when the pore foaming agent is used as well, in this setup, the liquid-phase reaction resulting from the addition of $\mathrm{CaCO}_{3}$ can prevent the existence of the cracks. Next, due to an increase in the sintering temperature from $600^{\circ} \mathrm{C}$ to $900^{\circ} \mathrm{C}, \mathrm{CaCO}_{3}$ decomposes to form $\mathrm{CO}_{2}$ gas. In this case, the weight loss was negligible. At an increase in the sintering temperature $600^{\circ} \mathrm{C}$ to $900^{\circ} \mathrm{C}$, the weight loss of the sample was paltry $-1.43 \%$. Then, due to an increase in the sintering temperature higher than $900^{\circ} \mathrm{C}$, the solid-phase reaction accelerates and, at the same time, the bonding phase of ceramics was believed to form while overheating. Therefore, the optimization of the sintering temperature should be of vital importance to compromise the competing relationship of strength and porosity of the sintered porous ceramics.

3.2. The Influence of the Stage Sintering Process in the Characteristics of the Porous Ceramics. In this study, the stage sintering process mainly lies on the sintering temperature, heating rate, and holding time. The influences of different preheating, sintering temperatures, heating rate, and holding times were determined with regard to the porosity, density, shrinkage, and compressive strength of the porous ceramics 

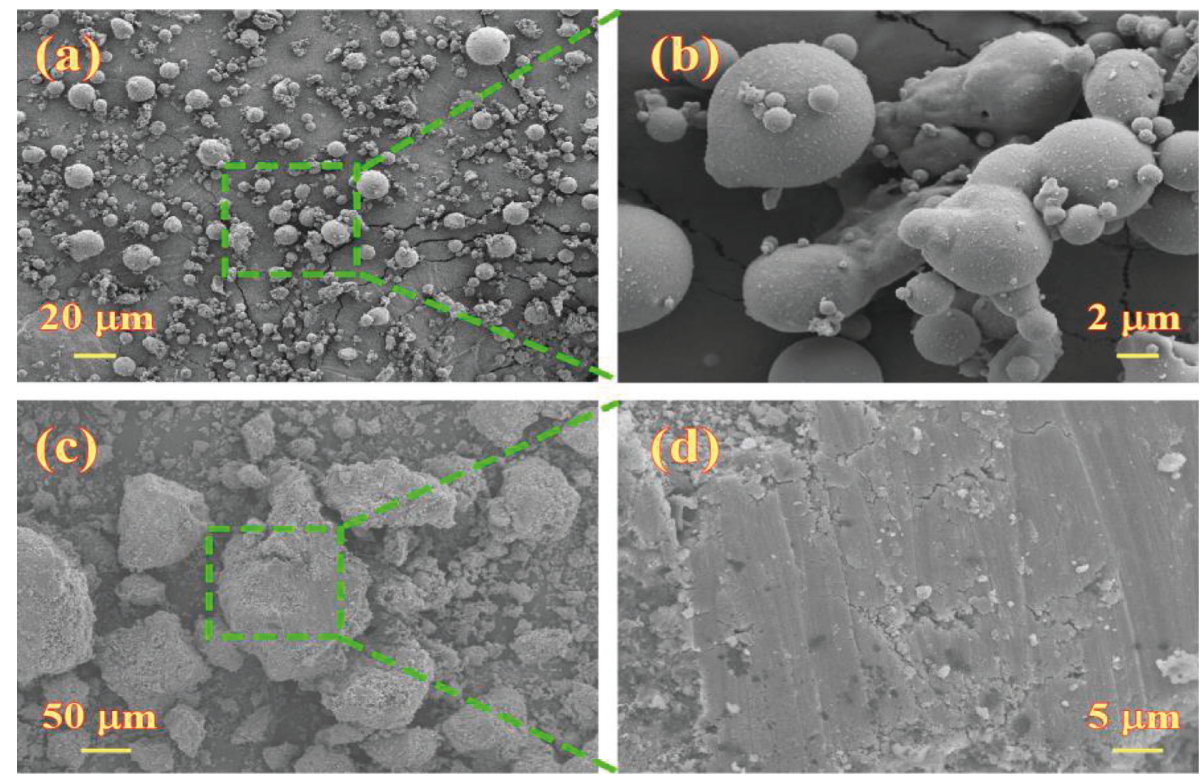

Figure 3: SEM images of (a, b) coal ash and (c, d) sewage sludge.

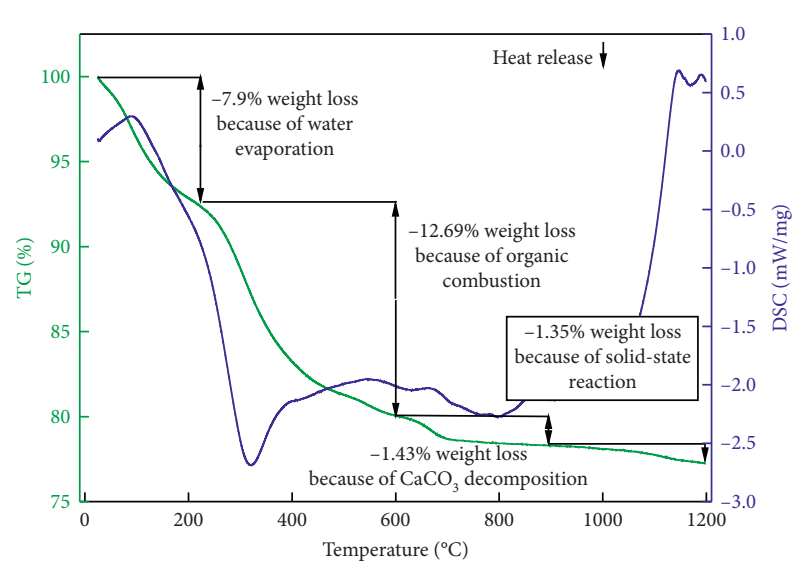

FIGURE 4: TG/DSC analysis of the mixture of sludge and fly ash.

understudied. Sections 3.2.1 and 3.2.2 contain the details of the influence of a one-stage and two-stage sintering process on the characteristics of the porous ceramics understudied.

3.2.1. Influence of One-Stage Sintering Process on the Characteristics of the Porous Ceramics. Figures 5-7 show the influence of the one-stage sintering process on the characteristics of the porous ceramics. On the one hand, as shown in Figure 5(a), it can be observed that increasing the sintering temperature from 200 to $300^{\circ} \mathrm{C}$ decreases the bulk density, whereas increasing the sintering temperature from 300 to $400^{\circ} \mathrm{C}$ increases the bulk density of the porous ceramics. Also, in Figure 5(a), it can be observed that the increase in the sintering temperature from 200 to $300^{\circ} \mathrm{C}$ increases the apparent porosity, whereas increasing the sintering temperature from 300 to $400^{\circ} \mathrm{C}$ decreases the apparent porosity of the porous ceramics. Still, in Figure 5(a), it can be observed that for the one-stage sintering process, at a specific sintering temperature of $300^{\circ} \mathrm{C}$, the bulk density is the lowest, whereas the apparent porosity is the highest. The reason for this trend is that there is a carbonization process in the organic matter during the heating process, and some of the organic matter (starch is the main factor) reacts with the oxygen in the air to form pores. Another part of the organic matter that cannot touch the air will carbonize. Thus, it could continue to make uniform pores in the subsequent sintering process with the oxygen generated at the high temperature of $\mathrm{Fe}_{2} \mathrm{O}_{3}$ to form pores, and this is more uniform than the pores formed by sintering of organic matter [6]. As indicated in Figure 5(a), it could be inferred that the influence of one-stage sintering process on the bulk density was less significant because it fell in the range of $0.89-0.95 \mathrm{~g} / \mathrm{cm}^{3}$.

On the other hand, as shown in Figure 5(b), the compressive strength and linear shrinkage decreases with the increase of the sintering temperature from 200 to $300^{\circ} \mathrm{C}$, whereas it increased with the increase in the sintering temperature from 300 to $400^{\circ} \mathrm{C}$. Still, in Figure 5(b), it can be observed that at a sintering temperature of $400^{\circ} \mathrm{C}$, the porous ceramics exhibited the highest compressive strength and linear shrinkage of about $4.3 \mathrm{MPa}$ and $8.9 \%$, respectively. As indicated in Figure 5(b), further increase in the sintering temperature higher than $400^{\circ} \mathrm{C}$ gradually decreases the compressive strength and linear shrinkage of the porous ceramics. The authors attributed the gradual decreasing of the compressive strength and linear shrinkage of the samples to the higher amount of gas released under the higher sintering temperature involved in this stage. Also, the authors believe some cracks could have occurred in the samples, resulting in deterioration of compressive strength. Overall, as shown in Figures 5(a) and 5(b), it can be observed that the linear shrinkage rate is $7 \sim 8.9 \%$, bulk density is $0.89 \sim 0.95 \mathrm{~g} / \mathrm{cm}^{3}$, apparent porosity is $61.4 \sim 65.5 \%$, and the compressive strength is $3 \sim 4.3 \mathrm{MPa}$.

In the current study, a preheating temperature of $300^{\circ} \mathrm{C}$ is considered the most suitable for the carbonization of organic matter, because of the indicated lowest bulk density 


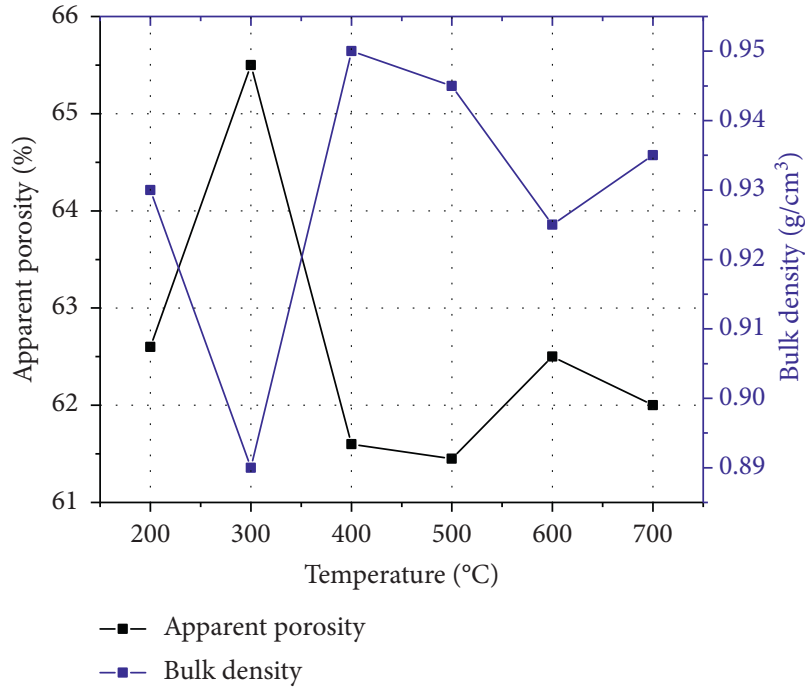

(a)

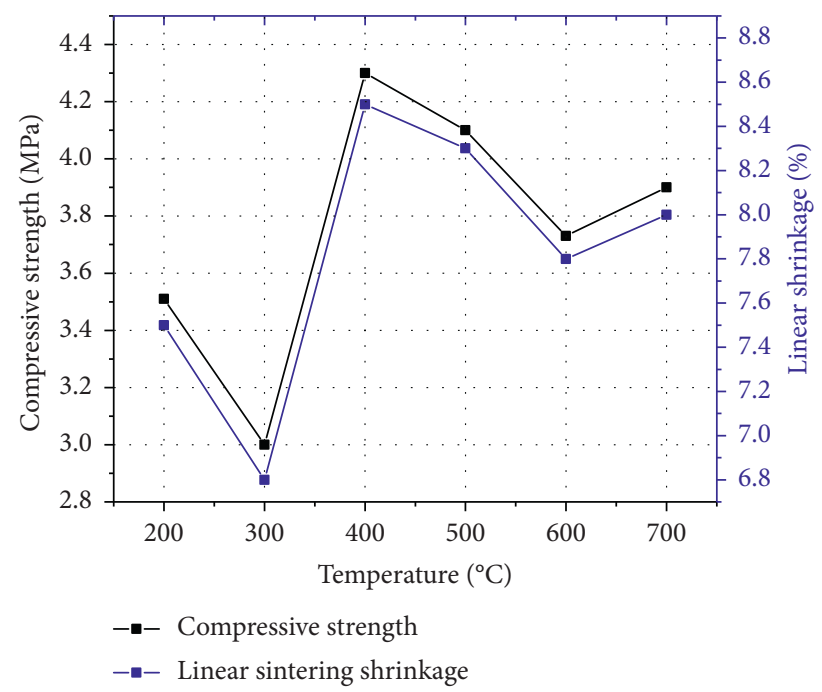

(b)

FIGURE 5: Influence of one-stage sintering process on (a) the apparent porosity and bulk density and (b) compressive strength and linear sintering shrinkage of the porous ceramics.

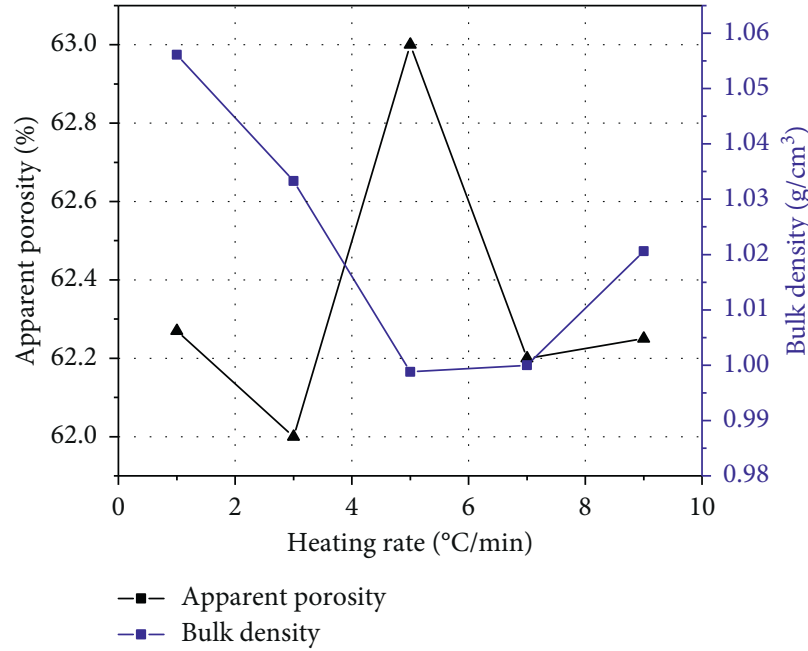

(a)

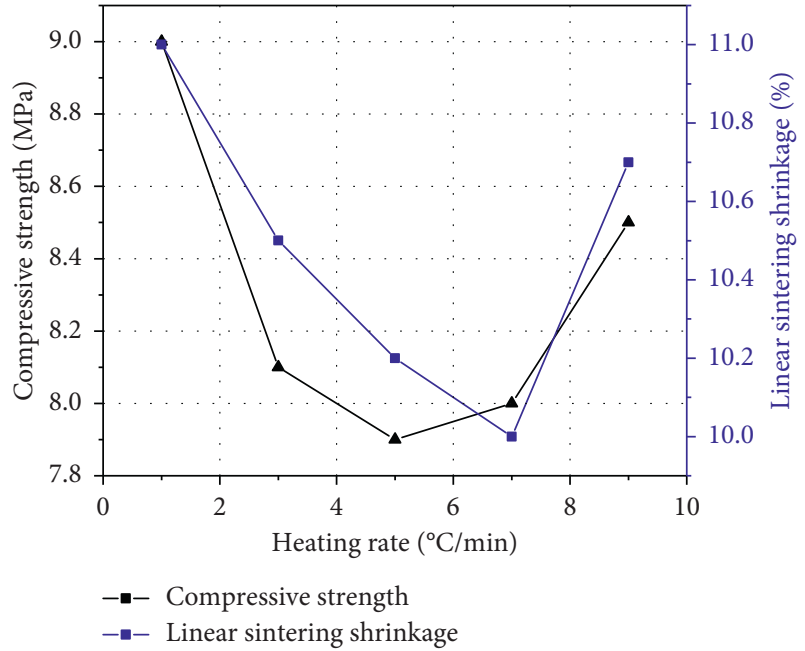

(b)

FIGURE 6: The influence of the heating rate on (a) the apparent porosity and bulk density and (b) compressive strength and linear sintering shrinkage of as-sintered ceramics for one-stage sintering process.

and the highest apparent porosity at this temperature. Similar results for one-stage sintering process in similar products were reported elsewhere $[27,31]$.

Figure 6 shows the influence of the heating rate on the characteristics of the porous ceramics. As shown in Figure 6(a), it could be observed that the porous ceramics exhibited the highest and lowest apparent porosity and bulk density, respectively, at a heating rate of $5^{\circ} \mathrm{C}$. It implies that at the heating rate of $5^{\circ} \mathrm{C} / \mathrm{min}$, the amount of carbonization of organic matter was the highest, contributing to the lowest value of bulk density and highest value of the porosity. Quantitatively, as indicated in Figure 6(a), the apparent porosity is $62 \sim 63 \%$, whereas the bulk density is
$0.98 \sim 1.05 \mathrm{~g} / \mathrm{cm}^{3}$. As shown in Figure 6(b), it can be seen that the compressive strength decreased sharply and continuously at a heating rate from 1 to $5^{\circ} \mathrm{C} / \mathrm{min}$, whereas it increased gradually at a heating rate from 5 to $7^{\circ} \mathrm{C} / \mathrm{min}$ and sharply from 7 to $9^{\circ} \mathrm{C} / \mathrm{min}$. Still, in Figure 6(a), it could be observed that the range of the compressive strength is 7.9 9 MPa for the range of the heating rate understudied. However, it is expected that the compressive strength of porous ceramics can be mostly controlled by subsequent second-stage sintering temperature. Furthermore, as shown in Figure 6(b), it is evident that the linear shrinkage decreased sharply and continuously at a heating rate from $1-7^{\circ} \mathrm{C} / \mathrm{min}$, and then it increased sharply at a heating rate 


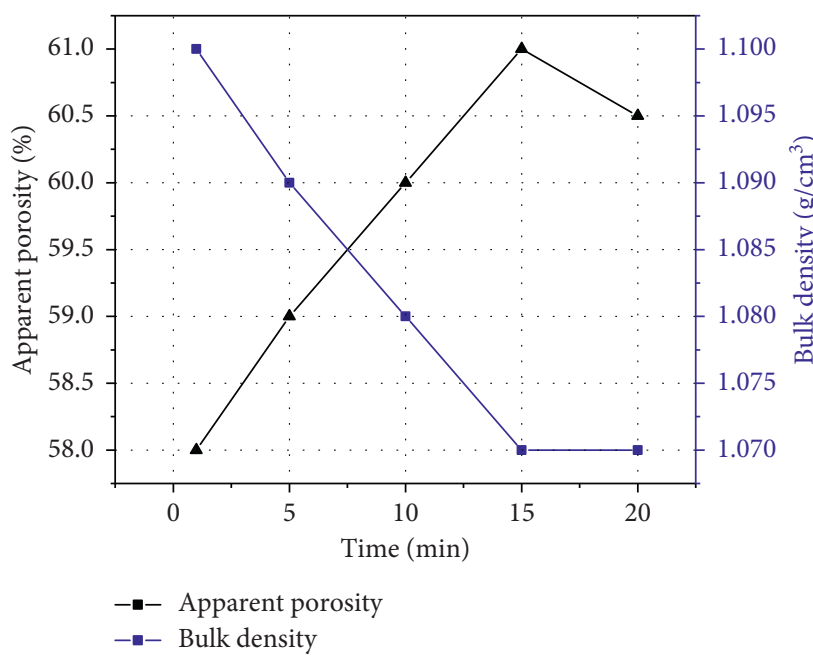

(a)

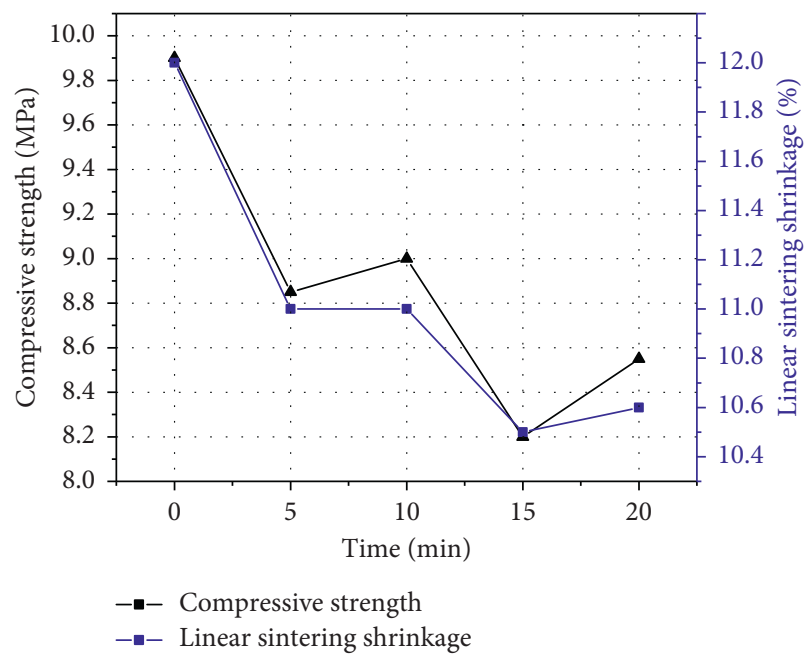

(b)

FIGURE 7: The influence of the holding time on (a) the apparent porosity and bulk density and (b) compressive strength and linear sintering shrinkage of as-sintered ceramics for one-stage sintering process.

from 7 to $9^{\circ} \mathrm{C} / \mathrm{min}$. As shown in Figure 6(b), it can be seen that the range of the linear shrinkage is 10 11\%. According to the results shown in Figure 6, it could be inferred that the variation of the heating rate in one-stage sintering process has minimal influence on the characteristics of the porous ceramics. The authors believed that the variation of the heating rate in the two-stage sintering process would give a more significant influence on the characteristics of the porous ceramics.

Moreover, Figure 7 shows the influence of the heating holding time of the one-stage sintering process on the characteristics of the porous ceramics. As shown in Figure $7(\mathrm{a})$, it can be seen that the apparent porosity increases with the holding time, whereas the bulk density decreases with the holding time, both upto $15 \mathrm{~min}$. Still, in Figure $7(\mathrm{a})$, it can be observed that the range of the apparent porosity is $58 \sim 61 \%$, whereas that of the bulk density is $1.07 \sim 1.1 \mathrm{~g} / \mathrm{cm}^{3}$. According to results indicated in Figure $7(\mathrm{a})$, a holding time of $15 \mathrm{~min}$ at $300^{\circ} \mathrm{C}$ would give the porous ceramics with the lowest bulk density and highest apparent porosity. The authors attributed these to the carbonization of the organic matters, and the generated carbon will continue to be a pore-forming agent in the subsequent sintering with the oxygen generated at the high temperature. Thus, the most conducive pores form, causing the lowest bulk density and the highest porosity.

Furthermore, as shown in Figure 7(b), the linear shrinkage and compressive strength of the sintered ceramics decrease with the increase in the holding time from 0 to 5 minutes, and then a small increase was observed at the holding time of 10 minutes. Still, in Figure 7(b), the range of the compressive strength is $\sim 8.2-9.9 \mathrm{MPa}$, whereas the range of the linear shrinkage rate is $\sim 10.5-12 \%$. An opposite happened for the porosity of the prepared ceramics. However, it should be noted that the influence of the holding time on compressive strength and porosity observed in this study is minimal compared with those obtained by previous studies $[25,30]$.
3.2.2. Influence of Two-Stage Sintering Process on the Characteristics of the Porous Ceramics. Figures 8-10 show the influence of the two-stage sintering process on the characteristics of the sintered ceramics. As shown in Figure 8(a), it can be observed that the apparent porosity decreases continuously with the increase in the heating rate, whereas the bulk density increases continuously with the heating rate for the rate investigated. Also, in Figure 8(a), it can be seen that the heating rate has a significant influence on the apparent porosity and bulk density in the two-stage sintering process. As indicated in Figure 8(a), the range of the apparent porosity is $\sim 52-64.5 \%$, whereas the range of the bulk density is $\sim 0.94-1.27 \mathrm{~g} / \mathrm{cm}^{3}$. Similarly, as shown in Figure $8(\mathrm{~b})$, the range of the compressive strength is $\sim 3.9-14.4 \mathrm{MPa}$, whereas the range of the shrinkage rate is $\sim 8.4-15 \%$. The authors believe the reason for this trend is that after the first stage, a large number of pore structures have been formed in the sintered ceramics due to combustion and carbonization of organic matter. Therefore, if the heating rate in the second stage is too fast, the decomposition of $\mathrm{CaCO}_{3}$ and the reaction between Cao and $\mathrm{Fe}_{2} \mathrm{O}_{3}$ are relatively high [35]. Thus, it will destroy the pore structure in the sintered ceramics. At the same time, the continuous reaction will increase the volume shrinkage of the sample. This will result in an irregular volume shrinkage, and the contact area between the particles is enlarged. The particle aggregation and the center distance are reduced, and a grain boundary is gradually formed as the temperature increases. Also, the volume continues to shrink and finally becomes a less porous polycrystalline.

Furthermore, Figure 9 shows the influence of the holding time on the characteristics of the sintered ceramics for the second-stage sintering process. As shown in Figures 9(a) and 9(b), it can be seen that the increase in holding time had a significant influence on the characteristics of the sintered ceramics. As indicated in Figure 9(a), the range of the apparent porosity is $\sim 52.4-58.5 \%$, whereas that of the bulk 


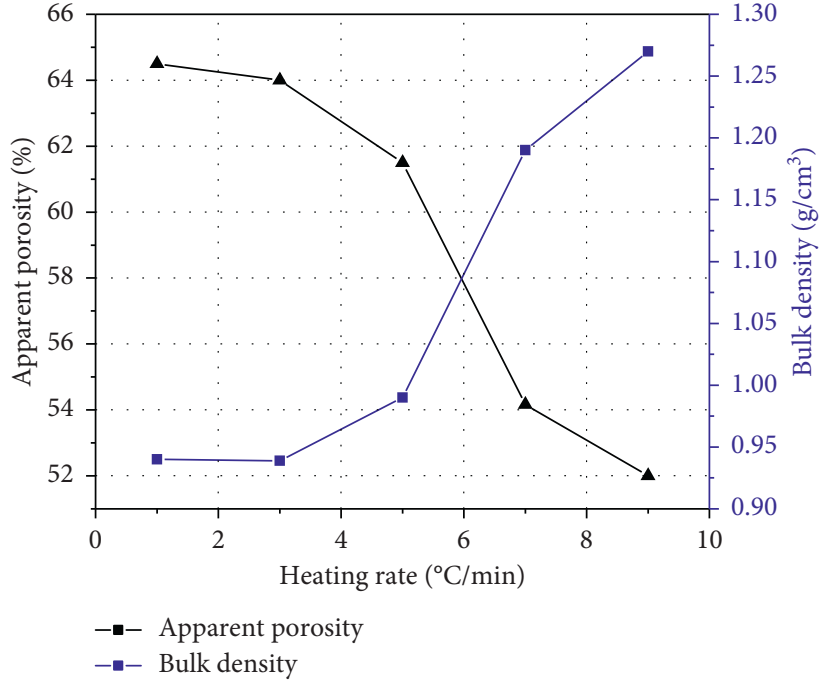

(a)

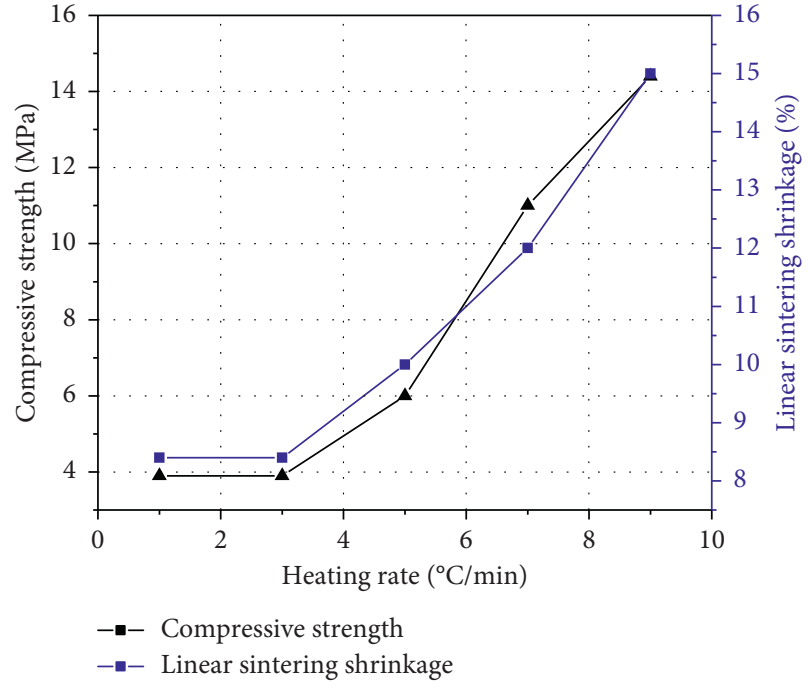

(b)

FIGURE 8: The influence of the heating rate on (a) the apparent porosity and bulk density and (b) compressive strength and linear sintering shrinkage of as-sintered ceramics for the second-stage sintering process.

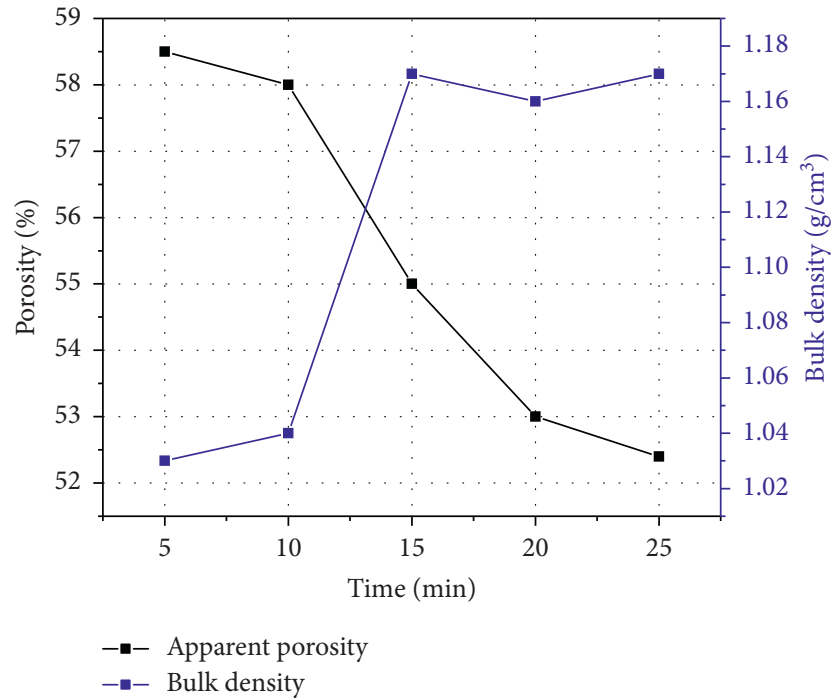

(a)

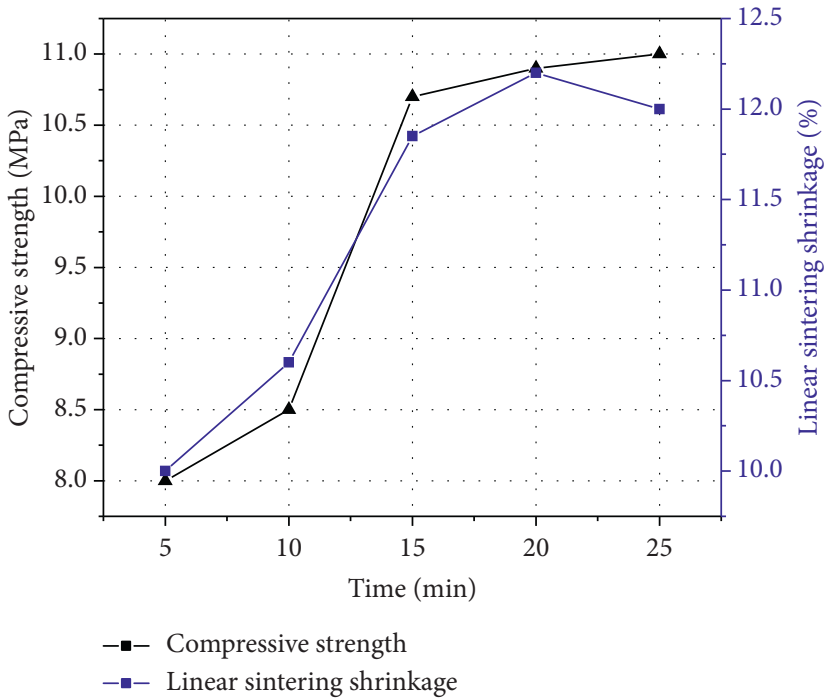

(b)

FIGURE 9: The influence of the holding time on (a) the apparent porosity and bulk density and (b) compressive strength and linear sintering shrinkage of as-sintered ceramics for the second-stage sintering process.

density is $\sim 1.03-1.17 \mathrm{~g} / \mathrm{cm}^{3}$. Also, as indicated in Figure 9(b), the range of the compressive strength is $\sim 8-11 \mathrm{MPa}$, whereas that of the linear shrinkage is $\sim 10.0-12.2 \%$. Also, it can be observed in Figures 9(a) and 9(b) that at the holding time higher than $15 \mathrm{~min}$, the performance of the sintered ceramics was relatively stable. The authors attributed this behavior of the sintered ceramics to the prolongated holding time, which allows the liquid phase in the sample to further encapsulate small grains, growth of the grains or secondary recrystallization, and closer bonding between the particles. As the reaction almost completed after holding for $15 \mathrm{~min}$, fewer changes were seen in the performance of the product.
Figure 10 shows the influence of sintering temperature on the characteristics of the sintered ceramics. Similar to those of the heating rate and holding time, the increase in the sintering temperature had a significant influence on the characteristics of the sintered ceramics. As shown in Figure 10(a), the range of the apparent porosity is $\sim 33.4-$ $71.1 \%$, whereas that of the bulk density is $\sim 0.72-1.66 \mathrm{~g} / \mathrm{cm}^{3}$. Also, as shown in Figure 10(b), the range of the compressive strength is $\sim 1.71-51 \mathrm{MPa}$, whereas that of the linear shrinkage is $\sim 3-22 \%$. These results are consistent with other studies carried out elsewhere [36-38]. It is worthy of note that the increase of the sintering temperature in the second- 


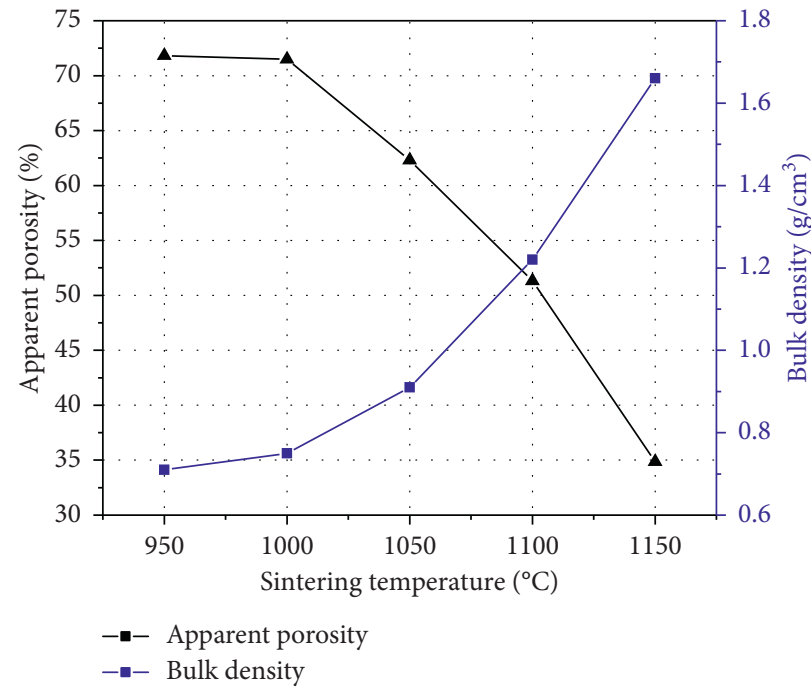

(a)

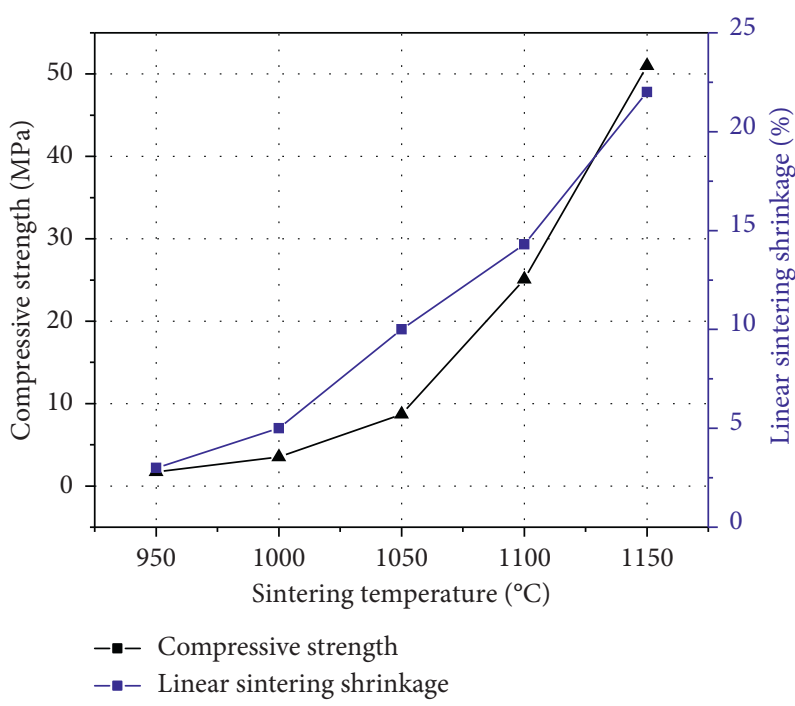

(b)

FIGURE 10: The influence of the sintering temperature on (a) the apparent porosity and bulk density and (b) compressive strength and linear sintering shrinkage of as-sintered ceramics for the second-stage sintering process.

stage sintering process causes the increase of the linear shrinkage rate and compressive strength at the expense of the apparent porosity. As shown in Figure 10(a), at the sintering temperature range of $1000^{\circ} \mathrm{C}-1150^{\circ} \mathrm{C}$, there was a continuous decrease of the apparent porosity.

On the other hand, the compressive strength and linear shrinkage of the sintered ceramic showed a significant increase at the sintering temperature of $950^{\circ} \mathrm{C}-1150^{\circ} \mathrm{C}$. The range of the compressive strength at this range of sintering temperature was $28-52 \mathrm{MPa}$, whereas those of the linear shrinkage was $1.27-1.66 \mathrm{~g} / \mathrm{cm}^{3}$ as indicated in Figure 10(b). The authors attributed these trends to the intensification of the solid-phase reaction in the sintered ceramics. In the beginning, part of $\mathrm{SiO}_{2}$ dissolved in the liquid phase fuses into the various crystal grains, thereby promoting the fusion of the grain boundaries and accelerating the whole densification process. After the temperature continues to rise, various substances begin to undergo chemical changes and elements such as calcium, sodium, silicon, and aluminum begin to dissolve together and form a feldspar phase [28].

At the same time, $\mathrm{SiO}_{2}$ will dissolve and embed into the skeleton of the porous ceramic, and thus the compressive strength, bulk density, and shrinkage increase but at the expense of the apparent porosity of the sintered ceramics. According to the results of the second-stage sintering process, it could be inferred that the characteristics of the porous ceramics understudied can be actively controlled by the two-stage sintering process.

\subsection{The Phase Composition and Microstructural Revolution.} Figure 11 shows the XRD patterns of the porous ceramics sintered at a temperature range from $950^{\circ} \mathrm{C}$ to $1150^{\circ} \mathrm{C}$. It can be observed in Figure 11(b) XRD pattern that the crystalline phase at a sintering temperature of $950^{\circ} \mathrm{C}$ only contains a small amount of feldspar $(\mathrm{Ca}, \mathrm{Na})(\mathrm{Si}, \mathrm{Al})_{4} \mathrm{O}_{8}$, except $\mathrm{SiO}_{2}$ (silica), $\mathrm{Al}_{6} \mathrm{Si}_{2} \mathrm{O}_{13}, \mathrm{Fe}_{2} \mathrm{O}_{3}$, and $\mathrm{CaCO}_{3}$. With the increase in the sintering temperature to $1000^{\circ} \mathrm{C}$ (as indicated in Figure 11(c) XRD pattern), $\mathrm{SiO}_{2}$ (silica) gradually reacts with mullite and $\mathrm{CaCO}_{3}$ to form albite $(\mathrm{Ca}, \mathrm{Na})(\mathrm{Si}, \mathrm{Al})_{4} \mathrm{O}_{8}$, and thus the peak intensity of feldspar keeps rising. Simultaneously, the peaks of $\mathrm{CaCO}_{3}$ gradually decrease until its disappearance at $1100^{\circ} \mathrm{C}$, indicating complete decomposition and transformation of $\mathrm{CaO}$ to feldspar (as indicated in Figure 11(d) XRD pattern). The XRD patterns of coal ash and sewage sludge in Figure 2 have proved the existence of $\mathrm{SiO}_{2}$ phase, some of which is believed to be involved in the reaction of feldspar formation. The rest of $\mathrm{SiO}_{2}$ (silica) continues to undergo liquid-phase transformation and fills into the pores of the sintered ceramics, which has been verified to cause the decrease of the apparent porosity and compressive strength in the porous ceramics understudied.

Figure 12 shows SEM images of the as-obtained porous ceramics sintered at various temperatures ranging from $950^{\circ} \mathrm{C}$ to $1150^{\circ} \mathrm{C}$. At $1000^{\circ} \mathrm{C}$ (Figure $12(\mathrm{a})$ ), the particles form a preliminary contact under the action of surface diffusion, and the sintering phenomenon is not much observable due to a loose accumulation state, indicating the solid-phase reaction is at the just beginning, and no liquid phase can be identified. Just for this reason, the compressive strength is only about $2 \mathrm{MPa}$, as indicated earlier in Figure 10 . With the further increase in the sintering temperature to $1050^{\circ} \mathrm{C}$, the liquid phase begins to appear as indicated in Figure 12(b), thereby forming bubble-like structures as clearly observable in the sintered skeleton. As the molten liquid phase begins to connect other solid-phase particles, the contact frequency 


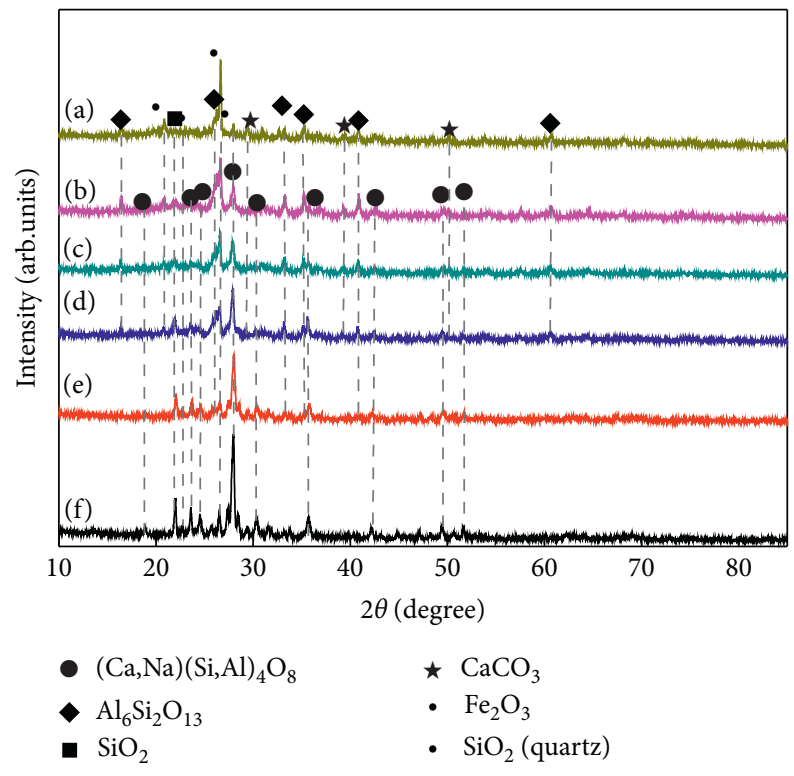

Figure 11: XRD patterns of (a) the mixed powder and the sintered samples at (b) $950^{\circ} \mathrm{C}$, (c) $1000^{\circ} \mathrm{C}$, (d) $1050^{\circ} \mathrm{C}$, (e) $1100^{\circ} \mathrm{C}$, and (f) $1150^{\circ} \mathrm{C}$.

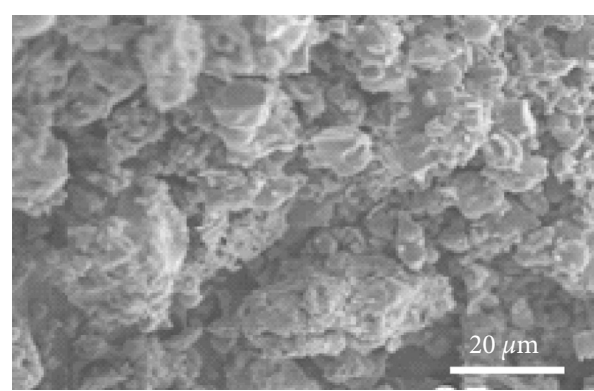

(a)

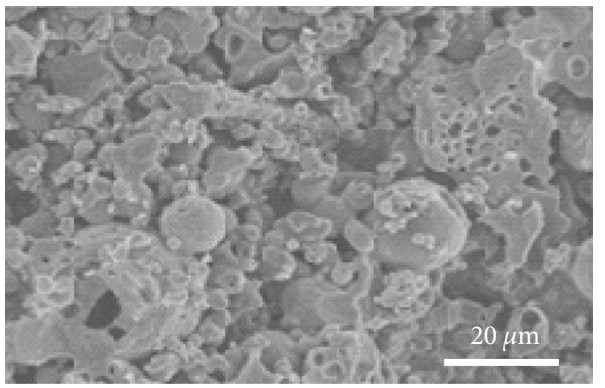

(c)

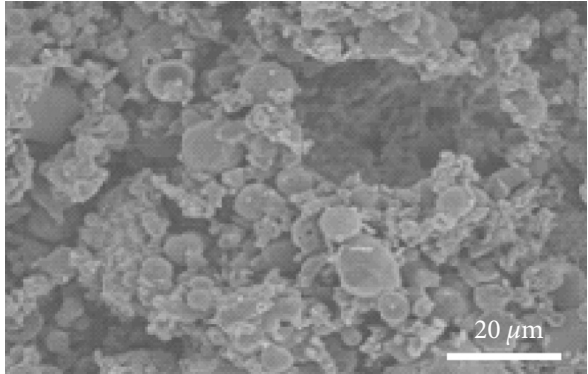

(b)

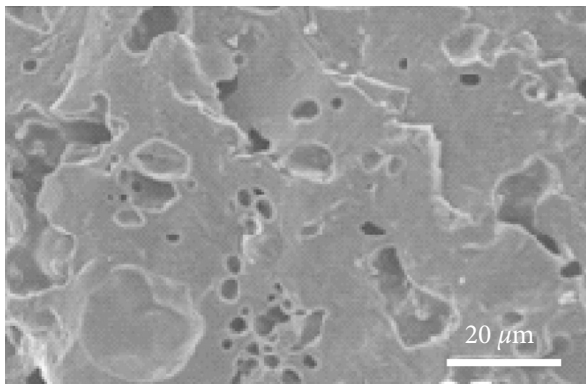

(d)

Figure 12: Fracture surface morphology of the sintered samples at (a) $1000^{\circ} \mathrm{C}$, (b) $1050^{\circ} \mathrm{C}$, (c) $1100^{\circ} \mathrm{C}$, and (d) $1150^{\circ} \mathrm{C}$.

among crystals is enhanced, promoting grain boundary dissolution and densification. At $1100^{\circ} \mathrm{C}$ (Figure 12(c)), together with the central open pores, some close pores also appear due to the blocking effect of the $\mathrm{CO}_{2}$ gas from the decomposition of $\mathrm{CaCO}_{3}$. As a result, the mechanical properties of the sintered ceramic would increase more rapidly. Such temperature of $1100^{\circ} \mathrm{C}$ has also been used as the optimum temperature for the preparation of porous ceramics by other researchers [39-41]. At $1150^{\circ} \mathrm{C}$ (Figure 12(d)), the open pores decreased significantly, and the matrix compactness is further enhanced to form the sludge coal ash into a block. At this sintering temperature, although the compressive strength is as high as $50 \mathrm{MPa}$, the apparent porosity decreased to about $30 \%$.

3.4. Influence of the Sintering Temperature on the Pore Size and Distribution. Figure 13 shows the influence of the sintering temperature on the pore size and distribution in the porous ceramics. As shown in Figure 13, it can be observed that the change in the sintering temperature causes slight variations in both compositional and structural. Still, in Figure 13, it 


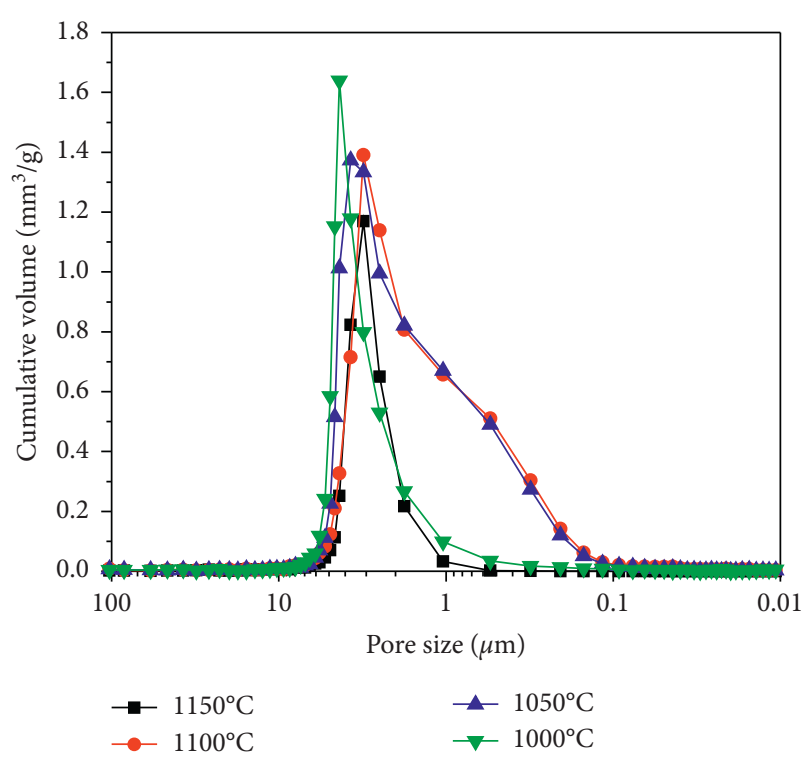

FIGURE 13: Influence of the sintering temperature on the pore size and distribution in the porous ceramics.

can be observed that the porous ceramics exhibited maximum cumulative volume in a pore size 3-4 $\mu \mathrm{m}$. It is believed that at the maximum pore size in the ceramics, feldspar phase begins to grow, the liquid phase has not been formed in large quantities, and the structure does not seem to be combined. Thus, the apparent porosity is substantial, the density is minimal, the compressive strength is small, and many of the pores could be formed. This phenomenon happens due to the sintering temperature being comparatively low for the production of porous ceramic less than $1100^{\circ} \mathrm{C}$, which shows that there are a large number of $\mathrm{SiO}_{2}$ on the surface of ceramic, less albite $\left(\mathrm{Al}_{6} \mathrm{Sil}_{2} \mathrm{O}_{13}\right)$, and where an incomplete-glassy phase is entrenched. The skeleton structure produced by feldspar and liquid-phase formation can be seen when the temperature reaches $1100^{\circ} \mathrm{C}$. At a temperature of $1100^{\circ} \mathrm{C}$, the fine bonding pore between grains begins to be fused, resulting in coarser and larger pores, some of which could exceed $15 \mu \mathrm{m}$. The porous ceramics sintered at this temperature have visible porosity and high mechanical strength, while the sample sintered at temperatures exceeding $1100^{\circ} \mathrm{C}$ has fewer pores and rougher surfaces. When the temperature increases to $1150^{\circ} \mathrm{C}$, the liquid phase increases further, and a large number of apparent pores are blocked. At this time, the combination method still produces an excellent pore-forming effect, leaving more pores in the ceramic body. The diameter of the pores is much larger than that formed at a lower temperature, and a large number of closed pores are formed due to the liquid-phase encapsulation.

\subsection{Pore-Formation Mechanism and Performance Comparison.} Figure 14 shows the schedule for preparing sewage sludgecoal ash porous ceramics. It can be divided into two stages. The first stage is from room temperature to temperature $\left(300^{\circ} \mathrm{C}, 400^{\circ} \mathrm{C}, 500^{\circ} \mathrm{C}, 600^{\circ} \mathrm{C}\right.$, and $\left.700^{\circ} \mathrm{C}\right)$. In this stage, a large

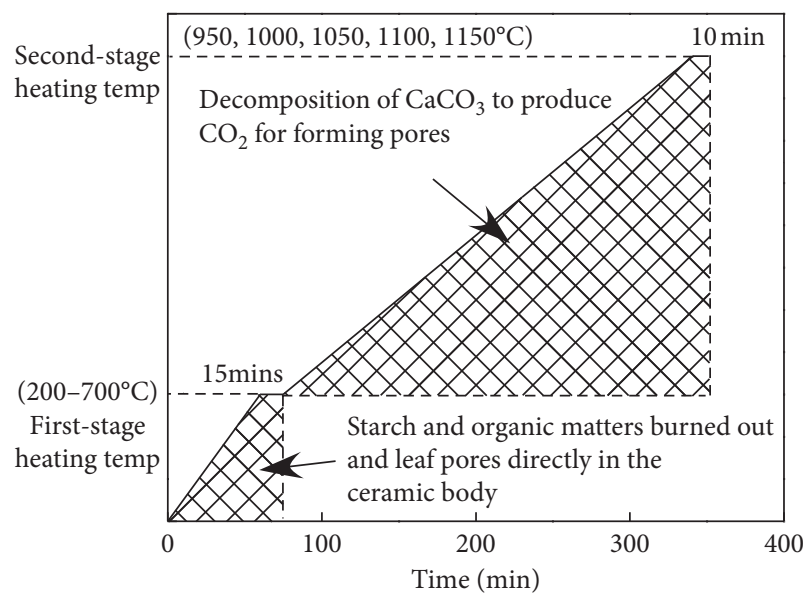

FIgURE 14: The schedule for preparing porous ceramics from fly ash/municipal sludge.

number of ceramic bodies are shaped into pores. The poreforming mechanism at this stage can be expressed as the starch, and organic matter burns out to leave pores directly in the ceramic body. However, the first stage is also the most dangerous because it involves an extensive exothermic reaction, which could damage the organic matter due to the formation of cracks. Therefore, the heating rate should be appropriately optimized for full combustion of the organic matter in contact with air or carbonization inside the compact for the pore formation in the second stage. The pore formation in the second stage depends on the decomposition of $\mathrm{CaCO}_{3}$ to produce $\mathrm{CO}_{2}$ in the ceramic matrix to form pores, and the oxygen in the air will continue to react with the carbon produced in the first stage to form pores.

Based on the above discussion, it could be inferred that in order to obtain some robust porous ceramics of this kind, first, it would require the first-stage sintering process at the temperature to $300^{\circ} \mathrm{C}$ at a heating rate of $5^{\circ} \mathrm{C} / \mathrm{min}$ held for $15 \mathrm{~min}$. Second, it would require the second-stage sintering process at the sintering temperature of $1100^{\circ} \mathrm{C}$ at a heating rate of $3^{\circ} \mathrm{C} / \mathrm{min}$ held for $10 \mathrm{~min}$. With these processes, the authors obtained the high-quality samples with an apparent porosity up to $51.3 \%$, density up to $1.22 \mathrm{~g} / \mathrm{cm}^{3}$, linear shrinkage up to $14.3 \%$, and comparable high strength of 25.1 MPa. These results were compared with the sintering parameters and performance of some porous ceramics prepared from clay and other wastes [3, 27, 39-43], ceramics prepared from wastes without natural resource [26, 44-47], and ceramics prepared from a natural resource without using any wastes [48], as listed in Table 2 of Appendix 1 (Supplementary Materials). The result shows that the porous ceramics prepared in this study are highly promising for real applications in consideration of the cost of manufacture as well as the performance (high porosity and high strength are obtained both as the two key factors).

\section{Conclusions}

In this study, according to the pore-formation mechanism, a two-step sintering strategy was proposed using sewage sludge and coal ash as raw materials, and starch/CaCO $\mathrm{CO}_{3}$ as a 
mixed foaming agent. The effect of sintering parameters on the properties of the sample was studied, and the related mechanism was discussed.

(1) The pore-forming process is divided into two stages: the first stage is the formation of pores by organic matter combustion and the second stage is the appearance of $\mathrm{CO}_{2}$ from the decomposition of $\mathrm{CaCO}_{3}$, which will be helpful for the further formation of pores in the as-consolidated ceramic body.

(2) The optimal sintering process is selected: the firststage heating rate is $5^{\circ} \mathrm{C} / \mathrm{min}$, the temperature is increased to $300^{\circ} \mathrm{C}$, and the holding time is $15 \mathrm{~min}$; the second-stage heating rate is $3^{\circ} \mathrm{C} / \mathrm{min}$, the maximum temperature is designed according to the actual production needs, and the holding time is $10 \mathrm{~min}$.

(3) XRD and SEM analyses indicated that the pores are staggered on the green body and connected. From the $1050^{\circ} \mathrm{C}$ grain growth to the $1100^{\circ} \mathrm{C}$ liquid phase began to block the pores, the optimal reaction temperature for making porous ceramics is between this; when the temperature reaches $1150^{\circ} \mathrm{C}$, the ceramic cross-section is almost invisible. Moreover, there is no longer a spherical structure unique to coal ash, indicating the complete reaction to form feldspar here.

(4) After sintering at the maximum temperature of $1100^{\circ} \mathrm{C}$ under other optimized parameters, a highperformance porous ceramic material was obtained, with an apparent porosity up to $51.3 \%$, density to $1.22 \mathrm{~g} / \mathrm{cm}^{3}$, line shrinkage at $14.3 \%$, and compressive strength of $25.1 \mathrm{MPa}$, which is quite competitive for real applications than most of those reported in literatures.

\section{Data Availability}

Data sets will be available upon reasonable request from the corresponding author.

\section{Conflicts of Interest}

The authors declare that they have no conflicts of interest.

\section{Acknowledgments}

The authors acknowledge the financial supports from Natural Key Foundation of Jiangsu Province (BK2011025), National Natural Science Foundation of China (50979028), and National Key R\&D Program of China (2018YFC1508704).

\section{References}

[1] K. -Y. Chiang, Y. -C. Chen, and K. -L. Chien, "Scrap glass effect on building materials characteristics manufactured from water treatment plant sludge," Environmental Engineering Science, vol. 27, no. 2, pp. 137-145, 2010.
[2] K. -L. Lin, J. -C. Chang, J. -L. Shie, H. -J. Chen, and C.-M. Ma, "Characteristics of porous ceramics produced from waste diatomite and water purification sludge," Environmental Engineering Science, vol. 29, no. 6, pp. 436-446, 2012.

[3] M. Franus, D. Hunek, and M. Wdowin, "Utilization of sewage sludge in the manufacture of lightweight aggregate," Environmental Monitoring and Assessment, vol. 188, no. 1, pp. 113, 2016.

[4] S. Luostarinen, S. Luste, and M. Sillanpää, "Increased biogas production at wastewater treatment plants through co-digestion of sewage sludge with grease trap sludge from a meat processing plant," Bioresource Technology, vol. 100, no. 1, pp. 79-85, 2009.

[5] K. -Y. Chiang, P. -H. Chou, C. -R. Hua, K. -L. Chien, and C. Cheeseman, "Lightweight bricks manufactured from water treatment sludge and rice husks," Journal of Hazardous Materials, vol. 171, no. 1-3, pp. 76-82, 2009.

[6] N. J. Lóh, L. Simão, C. A. Faller, A. De Noni, and O. R. K. Montedo, "A review of two-step sintering for ceramics," Ceramics International, vol. 42, no. 11, pp. 1255612572, 2016.

[7] C. Li, Y. Han, L. Wu, K. Chen, and L.-N. An, "Fabrication and properties of porous anorthite ceramics with modelling pore structure," Materials Letters, vol. 190, pp. 95-98, 2017.

[8] P. Shahmohamad, A. R. A. Ani, K. Maulud, and M. Nor, "Reducing urban heat island effects: a systematic review to achieve energy consumption balance," International Journal of Physical Sciences, vol. 5, no. 6, pp. 626-636, 2010.

[9] C. H. Ho, H. M. Lo, K. L. Lin, and J. Y. Lan, "Characteristics of porous ceramics from prepared from sandblasting waste and waste diatomite by the co-sintering process," Environmental Progress \& Sustainable Energy, vol. 38, no. 2, pp. 321-328, 2018.

[10] Z. Wan, X. Zhang, L. Guan et al., "Sintering kinetics of porous ceramics from high-alumina fly ash," Transactions of the Indian Ceramic Society, vol. 76, no. 3, pp. 171-175, 2017.

[11] P. S. Liu and G. F. Chen, "Fabricating porous ceramics," in Porous Materials, pp. 221-302, Elsevier Ltd., Amsterdam, Netherlands, 2014.

[12] K. Okada, A. Ooyama, T. Isobe, Y. Kameshima, A. Nakajima, and K. J. D. MacKenzie, "Water retention properties of porous geopolymers for use in cooling applications," Journal of the European Ceramic Society, vol. 29, no. 10, pp. 1917-1923, 2009.

[13] M. A. Trenado, M. M. Marjanedas, B. E. Berthelsen-Molist, and F. X. Janer-Adrian, "The exploitation of sludge from aggregate plants in the manufacture of porous fired clay bricks," Materiales de Construcción, vol. 66, no. 323, p. e093, 2016.

[14] T.T. In, V. Sata, K. Boonserm, and P. Chindaprasirt, "Compressive strength and microstructure analysis of geopolymer paste using waste glass powder and fly ash," Journal of Cleaner Production, vol. 172, pp. 2892-2898, 2016.

[15] S. H. Aljbour, "Production of ceramics from waste glass and Jordanian oil shale ash," Oil Shale, vol. 33, no. 3, pp. 260-271, 2016.

[16] J. Cui and E. Forssberg, "Mechanical recycling of waste electric and electronic equipment: a review," Journal of Hazardous Materials, vol. 99, no. 3, pp. 243-263, 2003.

[17] P. Falaciński, "Influence of fly ash from the thermal treatment of municipal sewage sludge on chosen properties of hardening slurries," Technical Transactions, vol. 3, no. 114, pp. 125-138, 2017. 
[18] J.-H. Eom, Y.-W. Kim, and S. Raju, "Processing and properties of macroporous silicon carbide ceramics: a review," Journal of Asian Ceramic Societies, vol. 1, no. 3, pp. 220-242, 2013.

[19] I. Sabree, J. E. Gough, and B. Derby, "Mechanical properties of porous ceramic scaffolds: influence of internal dimensions," Ceramics International, vol. 41, no. 7, pp. 8425-8432, 2015.

[20] D. O. Obada, D. Dodoo-Arhin, M. Dauda, F. O. Anafi, A. S. Ahmed, and O. A. Ajayi, "The impact of kaolin dehydroxylation on the porosity and mechanical integrity of kaolin based ceramics using different pore formers," Results in Physics, vol. 7, pp. 2718-2727, 2017.

[21] M. Prakasam, J. Locs, K. Salma-Ancane, D. Loca, A. Largeteau, and L. Berzina-Cimdina, "Fabrication, properties and applications of dense hydroxyapatite: a review," Journal of Functional Biomaterials, vol. 6, no. 4, pp. 10991140, 2015.

[22] C. R. Cheeseman and G. S. Virdi, "Properties and microstructure of lightweight aggregate produced from sintered sewage sludge ash," Resources, Conservation and Recycling, vol. 45, no. 1, pp. 18-30, 2005.

[23] G. R. Xu, J. L. Zou, and G. B. Li, "Effect of sintering temperature on the characteristics of sludge ceramsite," Journal of Hazardous Materials, vol. 150, no. 2, pp. 394-400, 2008.

[24] I. Merino, L. F. Arévalo, and F. Romero, "Characterization and possible uses of ashes from wastewater treatment plants," Waste Management, vol. 25, no. 10, pp. 1046-1054, 2005.

[25] K. Lin, K. Chiang, and D. Lin, "Effect of heating temperature on the sintering characteristics of sewage sludge ash," Journal of Hazardous Materials, vol. 128, no. 2-3, pp. 175-181, 2006.

[26] M. Romero, A. Andrés, R. Alonso, J. Viguri, and J. M. Rincón, "Sintering behaviour of ceramic bodies from contaminated marine sediments," Ceramics International, vol. 34, no. 8, pp. 1917-1924, 2008.

[27] Y. Qi, Q. Yue, S. Han et al., "Preparation and mechanism of ultra-lightweight ceramics produced from sewage sludge," Journal of Hazardous Materials, vol. 176, no. 1-3, pp. 76-84, 2010.

[28] B. Corrochano, J. Azcárate, and M. Rodas, "Effect of pre-firing and firing dwell times on the properties of artificial lightweight aggregates," Construction and Building Materials, vol. 53, pp. 91-101, 2014.

[29] E. C. Hammel, O. L.-R. Ighodaro, and O. I. Okoli, "Processing and properties of advanced porous ceramics: an application based review," Ceramics International, vol. 40, no. 10, pp. 15351-15370, 2014.

[30] U. Sutharsini, M. Thanihaichelvan, and R. Singh, "Two-step sintering of ceramics," Sintering of Functional Materials, pp. 3-22, 2018.

[31] B. Li, T.-C. Ling, L. Qu, and Y. Wang, "Effects of a two-step heating process on the properties of lightweight aggregate prepared with sewage sludge and saline clay," Construction and Building Materials, vol. 114, pp. 119-126, 2016.

[32] B. Corrochano, J. Azcárate, and M. Rodas, "Characterization of lightweight aggregates manufactured from washing aggregate sludge and fly ash," Resources, Conservation and Recycling, vol. 53, no. 10, pp. 571-581, 2009.

[33] C. Chen and H. Wu, "Lightweight bricks manufactured from ground soil, textile sludge, and coal ash," Environmental Technology, vol. 39, no. 11, pp. 1359-1367, 2018.

[34] H. Hu, K. Zhou, K. Meng, L. Song, and Q. Lin, "Effects of $\mathrm{SiO}_{2} / \mathrm{Al}_{2} \mathrm{O}_{3}$ ratios on sintering characteristics of synthetic coal ash," Energies, vol. 10, no. 2, p. 242, 2017.
[35] J. Yin, X. Lv, S. Xiang, C. Bai, and B. Yu, "Influence of $\mathrm{CaO}$ source on the formation behavior of calcium ferrite in solid state," ISIJ International, vol. 53, no. 9, pp. 1571-1579, 2013.

[36] N. Wei, "Leachability of heavy metals from lightweight aggregates made with sewage sludge and municipal solid waste incineration fly ash," International Journal of Environmental Research and Public Health, vol. 12, no. 5, pp. 4992-5005, 2015.

[37] X. Wang, Y. Jin, Z. Wang, Y. Nie, Q. Huang, and Q. Wang, "Development of lightweight aggregate from dry sewage sludge and coal ash," Waste Management, vol. 29, no. 4, pp. 1330-1335, 2009.

[38] M. Liu, C. Wang, Y. Bai, and G. Xu, "Effects of sintering temperature on the characteristics of lightweight aggregate made from sewage sludge and river sediment," Journal of Alloys and Compounds, vol. 748, pp. 522-527, 2018.

[39] M. Sutcu, H. Alptekin, E. Erdogmus, Y. Er, and O. Gencel, "Characteristics of fired clay bricks with waste marble powder addition as building materials," Construction and Building Materials, vol. 82, pp. 1-8, 2015.

[40] C. Martínez-García, D. Eliche-Quesada, L. Pérez-Villarejo, F. J. Iglesias-Godino, and F. A. Corpas-Iglesias, "Sludge valorization from wastewater treatment plant to its application on the ceramic industry," Journal of Environmental Management, vol. 95, pp. S343-S348, 2012.

[41] C.-H. Weng, D.-F. Lin, and P.-C. Chiang, "Utilization of sludge as brick materials," Advances in Environmental Research, vol. 7, no. 3, pp. 679-685, 2003.

[42] I. Demir, "Reuse of waste glass in building brick production," Waste Management \& Research, vol. 27, no. 6, pp. 572-577, 2009.

[43] E. Lodins, I. Rozenstrauha, M. Rundans, I. Sperberga, L. Krage, and J. Grabis, "Production of glass-ceramics from sewage sludge and waste glass," IOP Conference Series: Materials Science and Engineering, vol. 25, Article ID 012016, 2011.

[44] T. Liu, Y. Tang, L. Han, J. Song, Z. Luo, and A. Lu, "Recycling of harmful waste lead-zinc mine tailings and fly ash for preparation of inorganic porous ceramics," Ceramics International, vol. 43, no. 6, pp. 4910-4918, 2017.

[45] J. Qin, C. Cui, X. Cui, A. Hussain, and C. Yang, "Preparation and characterization of ceramsite from lime mud and coal fly ash," Construction and Building Materials, vol. 95, pp. 10-17, 2015.

[46] M. Sutcu and S. Akkurt, "The use of recycled paper processing residues in making porous brick with reduced thermal conductivity," Ceramics International, vol. 35, no. 7, pp. 2625-2631, 2009.

[47] D.-H. Vu, K.-S. Wang, and B. H. Bac, "Humidity control porous ceramics prepared from waste and porous materials," Materials Letters, vol. 65, no. 6, pp. 940-943, 2011.

[48] L. Hong, Z. Wang, S. Wang, and M. Xu, "Preparation of silicon carbide porous ceramics," IOP Conference Series Materials Science and Engineering, vol. 394, no. 2, p. 022070, 2018. 


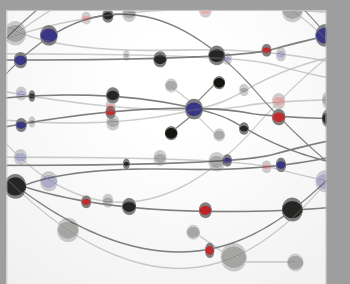

The Scientific World Journal
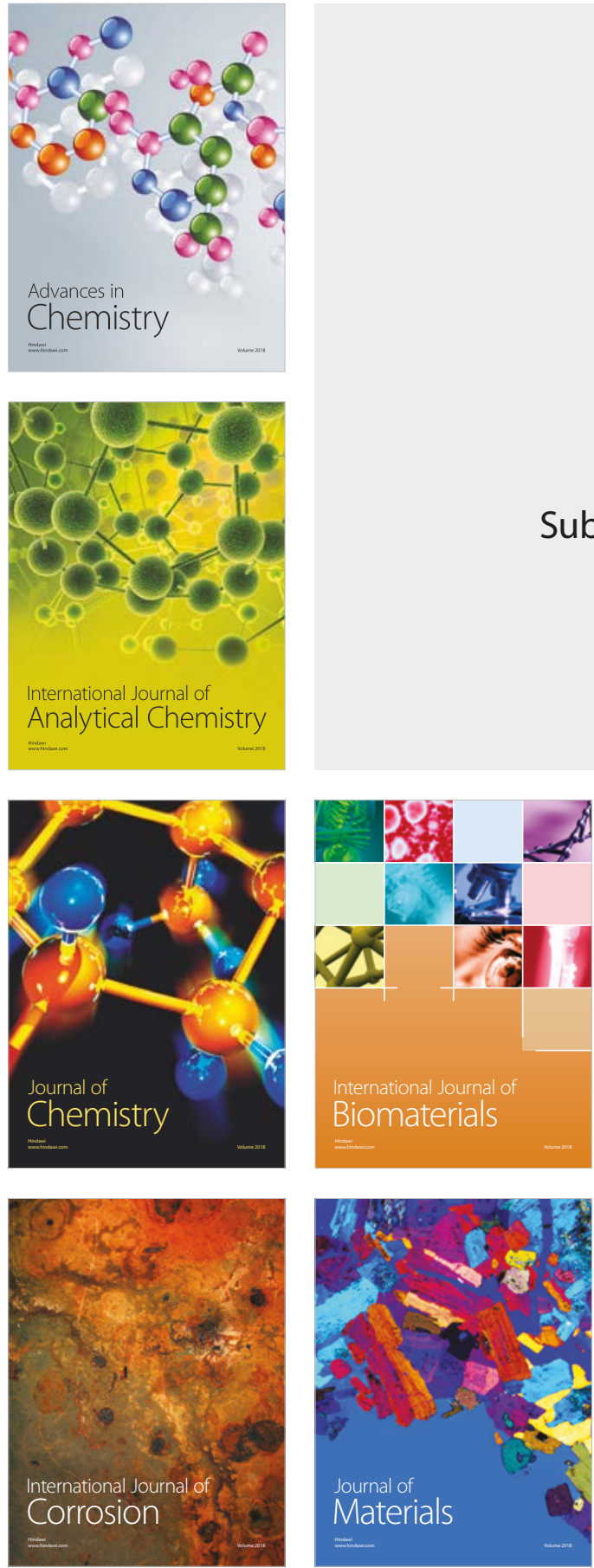

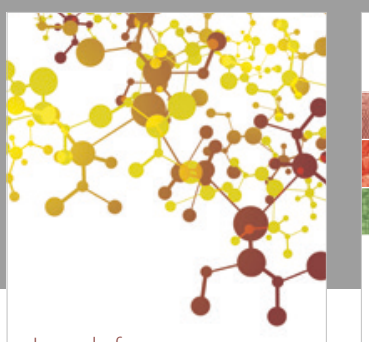

Journal of

Applied Chemistry
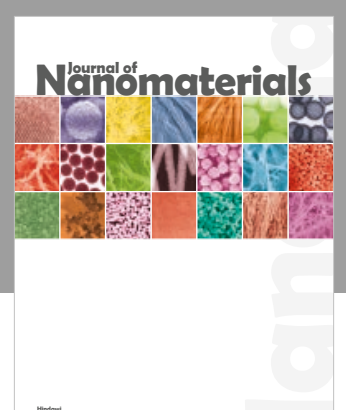



Scientifica

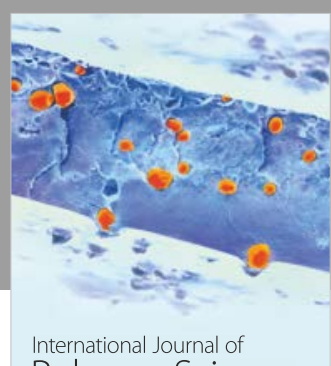

Polymer Science

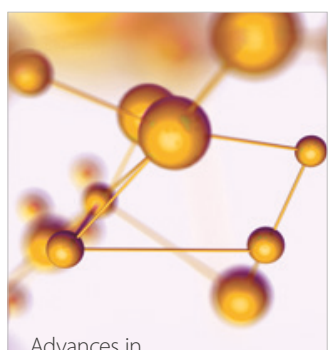

Physical Chemistry
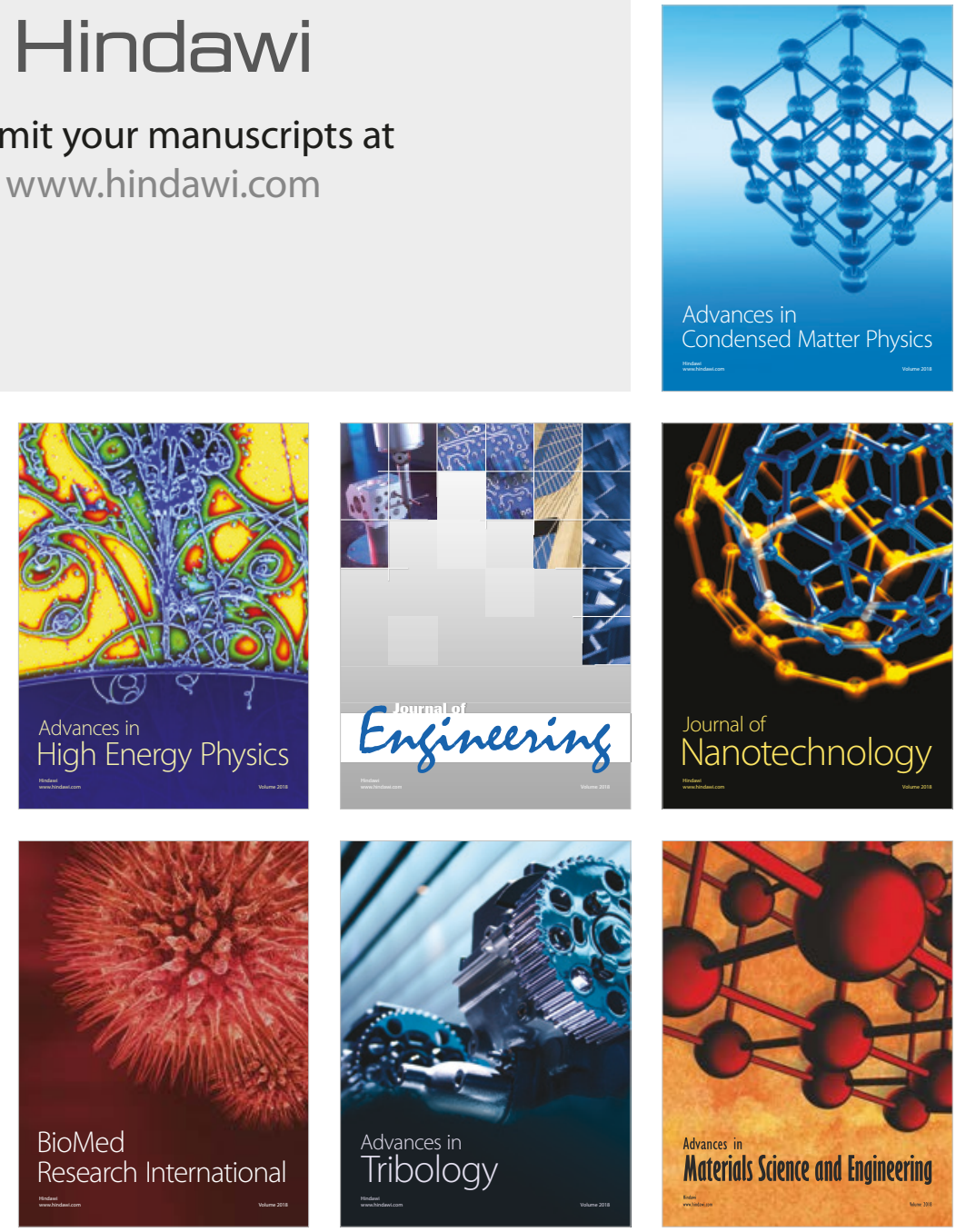